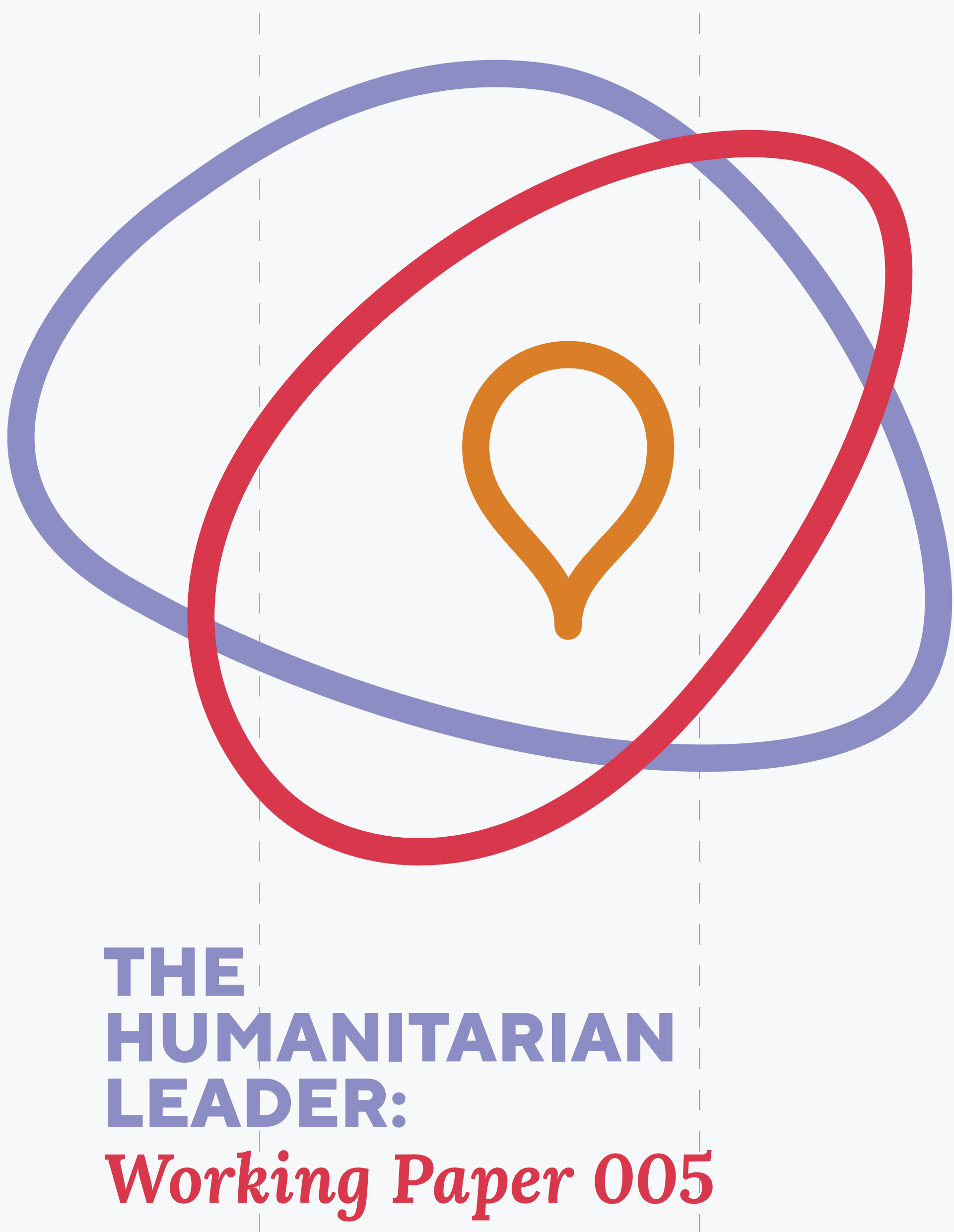




\title{
INSTITUTIONAL AMNESIA AND HUMANITARIAN DISASTER MANAGEMENT
}

\section{Alastair Stark}

\section{Working Paper 005}

\author{
February 2020
}

\section{The Centre For Humanitarian Leadership Deakin University Australia}

Dr. Alastair Stark

School of Political Science and International Studies

University of Queensland

Brisbane, Australia

alastair.stark@uq.edu.au

This paper was prepared for the Centre for Humanitarian Leadership.

The views expressed herein are those of the author and do not necessarily reflect the views of the Centre for Humanitarian Leadership. These papers are circulated for discussion and comment purposes. They have not been peer reviewed.

(C) 2020 by Alistair Stark. All rights reserved. 


\section{ABSTRACT}

Institutional amnesia is a serious concern for those who plan for, respond to and recover from humanitarian crises. Yet little effort has been made to understand its effects in disaster management generally and humanitarian agencies specifically. Consequently, we have no idea how to reform in ways which can deal with the issue of memory-loss. This paper addresses these concerns by defining institutional amnesia in conceptual and empirical terms, establishing its causes in the humanitarian policy space, ascertaining its effects within and across disasters and, most importantly, setting out a series of recommendations that can help humanitarian agencies address their own amnesia. The central argument is that institutional memory-loss is robbing individuals, organisations and networks of their lesson-learning gains. This is the single biggest reason why memory-loss must be acknowledged and treated as matter of some urgency. 


\section{Introduction}

Institutional amnesia is a metaphor that can be used to describe how individuals, organisations and interorganisational networks no longer recall lessons from the past that could help them perform tasks in the present. Around the world, public sector leaders have begun to identify memory-loss as a fundamental issue that undermines their attempts to learn about, design and deliver public policies (Stark 2018). In response, an amnesia-orientated research agenda has recently emerged within public policy and public administration scholarship (Corbett et al. 2018; Stark 2019; Stark and Head 2019). That agenda complements pre-existing research about institutional memory, which is most commonly produced in psychology (Wright and Gaskell 1995; Baddeley 2007; Kliegel et al. 2008), organisational studies (Walsh and Ungson 1991; Linde 2009; March 2010) and the social sciences (Connerton 1989; Halbwachs 1992; Misztal 2003).

Despite the widespread acknowledgement of the importance of memory-loss in these works, little effort has been made to properly understand the effects of institutional amnesia in relation to disaster management generally and humanitarian agencies specifically. This paper addresses these research gaps by:

- Exploring who and what 'forgets' in terms of disaster management and the various dimensions of memory-loss;

- Defining the causes of institutional amnesia in relation to the humanitarian policy space;

- Establishing the effects of amnesia within disasters, across disasters and in the humanitarian sector more widely;

- Proposing a series of practitioner-orientated recommendations about how problematic forms of amnesia might be addressed.

The key message for researchers and practitioners is that institutional amnesia undermines lesson-learning gains. This simple point - that institutional amnesia robs organisations of their learned-lessons - is the single biggest reason why memory-loss must be given a higher priority within humanitarian agencies. The first step towards achieving this is to initially recognise the importance of amnesia and, thereafter, bring memory retention practices into our lesson-learning. We can begin to do this by defining its nature and its effects.

\section{What is Institutional Amnesia?}

A simple of way of understanding amnesia is to think about how and where memory is retained. The most obvious way is through the memory of individuals with experience. Institutional amnesia is therefore created when experienced individuals, who have learned their own lessons via participating in disaster management activities, leave their professional environment and take their memories with them.
However, memory is also retained within organisations. This is done through a variety of methods. The first and most obvious way is via record-keeping. Over the past twenty years, changes in the ways in which public sector agencies record data (as more formal records give way to digital and internet based archiving) and changes in the nature and location of decision making (as formal 'on the record' styles of decision making give way to a more informal styles) have both led to the loss of a great deal of institutional memory (Pollitt 2000; 2009). Amnesia can therefore be understood through weaknesses in the quality of those processes that archive the past and allow staff to access historical lessons.

A second less obvious manifestation of organisational memory can be seen in the accumulation of standard operating procedures (SOPs) that institutionalise historical lessons. These are often the result of internal lesson-learning efforts that have identified issues and put in place reforms. Another dimension of institutional amnesia can therefore be measured in the decline or abandonment of procedures. This type of amnesia often occurs when no-one can remember why those procedures exist (Walsh and Ungson 1991; Stark 2019), which can happen if reforms in an organisation capture the lessons from the past but not necessarily the details of history (March and Levitt 1988). A failed operational response to a disaster, for example, may teach an agency that they need new contingency plans, better surge capacity or that their mutual aid relationships are performing poorly. Policies may be re-designed, new SOPs may be forthcoming and organisational memory may be enhanced as a consequence. Yet this does not guarantee that the history that propelled those lessons will be remembered. This poses a threat, particularly to procedures that are costly but not obviously related to an organisation's core business. For this reason, risk and crisis management practices are often forgotten or wilfully abandoned simply because they are not regularly used and no one recalls the history that justified their creation (Stark and Head 2019).

This alerts us to the fact that organisational memory also resides in an organisation's culture. Memory is not simply a tangible record of the past or a lesson that can be institutionalised procedurally. It is also organic, fluid and propagated through an organisation's 'storytelling' (Linde 2009). It can be found in the stories that are told about an organisation's creation, its traditions and its successes and failures (Boje 2008; Bevir and Rhodes 2010) and in organisational values and symbols that memorialise or curate the past (Edkins 2003). These cultural artefacts need not be organisationally specific.

Consider, for example, the powerful mythology surrounding the concepts of neutrality and impartiality that pervade the humanitarian policy space. These values imbue the culture of most humanitarian organisations and have a curated history themselves, which is often told and retold in terms of a variety of historical events in which they were challenged or validated (for examples of both see Weiss 1999 and Terry 2002). When we 
think about institutional amnesia from this view it will therefore reflect an absence of cultural processes and artefacts that interpret the past.

Memory can also reside across organisations in networks (Corbett et al. 2018). Transformations in the nature of disaster management over the past three decades have translated it from a state-centric and hierarchical affair to something which demands much more network governance (Stark 2014). In this context, memory can be shared across many different inter-connected actors. There are (at least) two dimensions to interorganisational memory of this nature. The first relates to the memory that is created via repeated interactions across time when different organisations need to come together to perform tasks. Repeated interactions of this nature lead to the creation of formal and informal interorganisational forums and shared forms of storytelling (Corbett et al. 2018). A simple example here comes via the coordination mechanisms that are used to respond to emergencies and disaster, which are often held together via informal and organic relationships that have been built over time (Moynihan 2008). A second dimension of network memory relates to 'external memory', which is held beyond an organisation's borders. For example, Stark (2018) has made the case in relation to disease control, flood management and bushfire policy, that external actors who exist beyond the borders of government are a valuable commodity because of their capacity to hold onto crisis management lessons for longer periods. These types of organisation - in the form of professional associations, advocacy groups, research centres and think tanks, for example - are often lesser amnesiacs simply because they are shielded from the political impulse to continually reform. These two types of memory show us that, from a network perspective, amnesia can be measured in a loss of interorganisational understanding and coherence.

\section{What Causes Institutional Amnesia?}

The single biggest cause of institutional amnesia is organisational 'churn' which is evidenced primarily through turnover in staff. Humanitarian NGOs suffer from significantly higher rates of turnover than other not-for-profit actors (Korf et al. 2015). Turnover is caused by many factors, the single largest of which is undoubtedly funding continuity, which encourages short-term contracting in all NGOs (Richardson 2006; Korf et al. 2015). However, there is more to the turnover issue than staffing costs. For example, should a humanitarian agency wish to keep its staff for more than one crisis deployment, they will often find themselves up against a widespread perception that humanitarian work, particularly in emergencies, is a one-off for the CV rather than something to be pursued across the longerterm. Doctors, for example, often view their involvement in an international emergency response as something to be done once, either as a form of volunteering or as a one-off episode in their training, rather than something that represents a permanent career choice (Henry 2004). This perception is often compounded by the lack of meaningful career pathways for professionals and the (relatively) low wages in the humanitarian sector (Richardson 2006; Telford and Cosgrave 2007). High levels of turnover can also be attributed to the nature of the job itself: long absences away from home, the insecurity of disaster zones and the trauma that can be experienced within them can all influence an individual's willingness to participate in multiple deployments. For these reasons, humanitarian workers with partners and families are less likely to remain within an NGO for long enough to experience more than one disaster (Korf et al. 2015). Thus, what we see is a variety of structural, organisational and personal issues combining to run against the grain of long-term employment and memory retention in the sector.

However, churn can also be created intentionally. Shortterm contracts, it has been argued, can be beneficial to a humanitarian organisation as a means of creating adaptive capacity in crisis responses (Korf et al. 2015). The need to quickly ramp up a relief effort, to adapt it to circumstance and to then de-scale it as events change may demand human resource strategies that are highly flexible. Moreover, it can also been argued that shortterm contracts allow for a form of sectoral learning, which is created by staff moving across agencies, jurisdictions and roles but not leaving humanitarian work entirely.

Churn is also side effect of the ceaseless political need to be seen reforming policy, restructuring organisations and showing change (Pollitt 2000). This political impulse is universal to all policy areas and disaster management is no exception. Indeed, the problem is particularly pronounced in multi-level systems of governance, such as that which structures Disaster Risk Reduction internationally, that have a division of labour between policy formulation and policy implementation. In such systems, there is a tendency for the centre to ceaselessly create policy regardless of the capacity of local units to implement it. Continual upheaval of this nature can encourage churn in policy ideas, frameworks for action and institutional apparatus which all create a form of amnesia as policy operates without clear beginnings or ends and exists in a perpetual limbo. In this context, actors on the ground can wilfully 'forget' initiatives imposed from above. This is often an organisational coping strategy that allows front-line actors to ignore what they cannot do in order to focus on what they can (Stark 2018).

A variety of other dynamics can also erode memory. One interesting argument suggests that we create amnesia by neglecting to use history in lesson-learning efforts. At least three versions of this neglect are recorded in crisis management research. One relates to the way in which crises are viewed as exceptional, which leads to an underappreciation of the value of learning from history (Terry 2002). There is a tendency, well documented in studies of crises and hindsight learning, to view crises as one-offs that could not be foreseen and will not be repeated (Boin and Fischbacher-Smith 2011; Hindmoor and McConnell 2013). This tendency sits comfortably 
with views about the contemporary nature of crises more generally, which emphasise the contemporary disaster as a unique manifestation of the highly uncertain times in which we live (Beck 1992). Complex emergencies are one label that has been used to define crises in these ways (for example, Natsios 1995). Yet when we look at complex emergencies, they actually reflect enduring problems that have not changed much across the years (Terry 2002). Consequently, we should not see them as exceptional or abnormal events which are characterised by unique forms of complexity but rather as more typical threats which can be understood through history (Terry 2002).

The neglect of history can also be a consequence of a wilful disinterest in learning about the past. This may be because confronting the past will challenge powerful interests, involve reforming the status quo or, more commonly, create political problems for incumbents and contemporary policies (Stark 2019). Thus, amnesia can be created through a simple unwillingness to interrogate the past because that means challenging dominant norms in the present. An illustrative example of this can be seen in the ways in which humanitarian aid continues to be militarised by governments in the global north. This is because of a continuing belief that aid is a policy tool for ensuring security. Continuity in this regard, Barakat et al. (2010) argue, reflects a willful tradition of the north deliberately ignoring the many failures that expose the lack of connection between humanitarian aid, the pacification of domestic communities and the creation of security.

A final category worth noting under the wilful neglect of history relates to the positive nature of institutional amnesia as a means of overcoming trauma. For example, trauma-inducing disasters can create 'long shadow crises' ('t Hart and Boin 2001). This description captures how acute emergencies shape-shift into political crises. Long-shadow crises are often driven by those who suffered trauma as they constantly relive the past in ways which will not allow them to move on. For these groups, the political struggle is endless because they cannot put distance between themselves, the disaster and their trauma. Efforts to produce accountability, redress and compensation after disasters will never be enough for these groups because 'those who make politics out of pursuing such claims make themselves, and those they charge, slaves to what cannot be changed' (Olick and Demetriou 2006: 77). Although many traumatic events are met with a response that emphasises that 'we will remember', the debilitating effects of trauma and resentment can actually mean that some amnesia can help, simply because 'memory breathes revenge as often as it breathes reconciliation' (Assmann 1999: 15).

\section{The Effects of Institutional Amnesia}

Amnesia can create problematic effects within disaster responses, across disasters and in the humanitarian aid sector more broadly. Within disasters, the single largest problem emerges from the handover process through which staff replace each other. As staff rotate, memory of the emergency effort can be lost, and the wheel is reinvented both in terms of strategic decision making and operational actions (Richardson 2006; Telford and Cosgrave 2007). Typically, handovers occur as emergency relief begins to give way to longer term recovery and development. As handovers happen in a crisis, memory of the needs of those affected, memory of the ad-hoc responses to the challenges of the emergency (some successful, others failed) and memory of the temporary relationships created on the front-line can all be lost. This may be because no systems are in place to bridge the gap. Alternatively, incoming staff (especially medical professionals) may orientate towards a form of 'learning by doing' which demands trial and error working at a personal level. Thus, the wheel (even if broken) is reinvented again and again across the life of an emergency response. Consider, for example, the account below, which many front-line humanitarian actors will recognise as familiar. It comes from the reconstruction of a 'day in the life' of a nurse on a Médecins Sans Frontières emergency project:

First, she works alongside the newly arrived doctor. She has noticed that this doctor does not want to listen to anything about how his predecessors did the job; he wants to do it his own way and to find things out by himself. For Anna this is an inefficient 'learning-by-doing' approach that fails to take into consideration the experiences of others. With the high staff turnover in this emergency project, knowledge just slips away. (Hilhorst and Schmiemann 2002: 495, emphasis added)

A second issue created by amnesia relates to the lack of skills within a relief effort. When churn limits the number of individuals and organisations with experience of previous crises, mistakes can be made. This is particularly true in relation to large-scale events that require surge capacity. When humanitarian NGOs attempt to 'ramp-up' in order to address the very largest and most disastrous events, they often need to staff relief responses with people who have little experience. Well-known problems in the response to the 2004 Indian Ocean Tsunami, for example, have been attributed to the inexperience of NGO workers (Telford and Cosgrave 2007). Issues including fraud, excessively paternalistic forms of aid, a lack of local empowerment and the overuse of an asset-driven approach to relief, for example, have all been associated with the drafting in of inexperienced humanitarian workers to that crisis. However, issues of that nature are by no means confined to that example. They need to be understood as a long-running feature of humanitarian responses more generally that have been well-recognised for some time (other examples can be found in Hicks and Pappas 2006 and Loquercio et al. 2006).

Amnesia also undermines trust in relationships. This is an important issue in relation to several areas of a crisis response. In strict operational terms, supply chains can suffer due to amnesia. Logistics research has shown how constant turnover within a crisis response can undermine the trust that is required to build swift 
supply lines in contexts of uncertainty (Tomasini and Van Wassenhove 2009; Tatham and Kovacs 2010; Dubey et al. 2016). Capacity building, participation and empowerment at the local level can also suffer because of amnesia-driven mistrust. The cosmetic nature of a great deal of participatory approaches to disaster management is now well-known (see, for example, Clarke et al. 2010). Local capacity building efforts, however, become even harder when staff turnover exacerbates power-sharing differences (Rothe 2012). Moreover, in certain regards, the lack of experienced staff in INGOs can undermine the capacity of local NGOs. The failure to include and empower grassroots development agencies in international disaster responses is a wellknown problem (see, for example, Stumpenhorst et al. 2011). In certain crisis responses, the experience of local staff, which will be underscored by the lack of experience in INGOs, can mean that they are 'poached' by international actors (Telford and Cosgrave 2007). While this may empower the individual and, potentially, enhance the context-sensitivity of a crisis response, it can also create memory-loss at the local level.

The effects of amnesia within a disaster response are compounded by its effects across disasters. The fundamental issue here is the way in which institutional memory-loss affects formal lesson-learning efforts. When it comes to lesson-learning, the default position of most researchers is that a great deal of learning from crises fails to reform policy and organisations successfully (for a very small sample see, Perrow 2007; Elliott 2009; Drennan et al. 2015; Eburn and Dovers 2015). This position allows crisis researchers to explain long-running patterns in the causes of crises, in the ways in which they go undetected, and in the ways in which they are mishandled. However, when we place the concept of amnesia into these views it opens up an alternative explanation as to why we see problematic repetitions of past problems. It may not always be the case that governments are failing to learn but rather that amnesia is undermining learning efforts (Stark 2018).

There are two dimensions to this problem. The first relates to the quality of lessons which can be affected by the recycling of old ideas (Pollitt 2009). When old solutions, which have tried and failed, are forgotten about they can remerge as something new only to fail again. Thus cyclical problems continue. The continual waxing and waning of centralisation versus decentralisation as principles that ought to structure crisis response frameworks is a good example here. However, disaster management literature is replete with examples of poorly performing policies being continued. Barakat et al (2010: 5310), for example, discuss the constant use of Quick Impact Projects (QIPs) and 'self-help' projects in conflict zones. Rather than generating legitimacy and support both kinds of project tend to 'instil a sense of pessimism among beneficiary populations that broader and more meaningful improvements in economic conditions may never arrive'. However, despite this failure, variations of these projects continue to be used. Thus, 'the cyclical resurrection of previously problematic paradigms may be viewed as a failure of institutional learning' (Barakat et al. 2010: 5297).

A second, more straightforward aspect to the amnesialearning relationship relates to the erosion of lessons across time (for example, see Colten and Sumpter 2009). For this reason, successful learning may rest upon the creation of what psychologists' call 'prospective memory'. This is when knowledge is stored in a way that is not used in the present or the everyday yet remains available for performing tasks in the future (McDaniel and Einstein 2007; Kliegel et al. 2008). Thus, the challenge for post-crisis learning is to find ways to institutionalise lessons so that they can be shared across time so that when the next crisis arrives, prospective memory can be put into practice. This challenge takes us to a discussion of how we might address amnesia.

\section{How Can We Cure Amnesia?}

There are two caveats worth noting before prescriptions for remedying amnesia can be proposed. First, it is almost impossible to foresee a future in which institutional amnesia can be completely cured. We therefore need to resist the urge to demand the impossible because, quite simply, some of the causes of amnesia are simply too big to fix. It is highly unlikely, for example, that humanitarian NGOs, are going to be able to find the levels of continuous donor funding that will transform the sector into an attractive job market with high levels of pay, enduring job security and many career opportunities. For the same reason, the reliance of NGOs on short-term contracts is also here to stay. The urge to instigate reform amongst politicians and organisational leaders is also unlikely to dampen any time soon as reform is always more attractive than inaction. Similarly, at the individual level, the view that participating in an emergency relief effort is a one-off voluntary endeavour will also remain despite the ever-increasing professionalisation of the sector. Finally, the massive personal challenges of working in a disaster zone means that continual turnover within a crisis response is inevitable. Therefore, the structural, organisational and personal causes of churn, and their amnesia inducing effects, are here to stay.

The second caveat that needs to precede any recommendations in this area is that certain kinds of amnesia can be beneficial and should not be treated as a problem. Forgetting the past is a necessary part of changing policies and practices that do not work (de Holan 2011). An over-reliance on history in decisionmaking can stifle creativity (Weick 1988) and amnesia can be a means of ameliorating traumatic institutional memories (Bell 2006). Therefore, an agenda that sets out to reduce amnesia needs to first ask what memories need to be recalled, which ones are best forgotten and how a balance can be struck between both these positions in a specific context. Despite these caveats, humanitarian agencies might consider several ways in which they could go about improving their memory. 


\section{Introduce Memory Work into \\ Lesson-Learning.}

Knowledge retention and knowledge recall measures can ensure learned lessons are more likely to have a prospective impact.

One method for achieving knowledge retention is to designate a specific monitor to oversee the implementation and the ongoing use of learned lessons. Innovative forms of public inquiry conducted in Australia and beyond, for example, have shown how the creation of independent monitors have kept recommendations alive over a period of years (Stark 2018). Ideally, these kinds of lesson-learning watchdogs would be external, independent and have the capacity to conduct their own research. A good Australian example can be found in the Bushfires Royal Commission Independent Monitor who over a five-year period following the Black Saturday Bushfires published a series of reports about the ongoing implementation of the Royal Commission's reform agenda. This ensured that the lessons remained on the agenda years after the Commission finished reporting. While this is a good example of an external knowledge recall mechanism, there is nothing that precludes an internal unit or even a singular member of staff from performing this role if given the proper capacity.

A second means of recalling lessons-learned relates to memorialisation, which is one means through which cultural forms of remembering can take place. Occasions which remember the victims and the survivors of disaster also offer an opportunity to recall specific lessons from that event. Regardless, of the specifics, the key message remains that lesson-learning without memory is meaningless.

\section{Take Record-Keeping Seriously.}

Develop archival processes that not only record organisational history in detail but can be easily accessed and disseminated. View record-keeping as a means of lesson-learning. The easiest way to take record-keeping seriously is to appoint a historian as an archivist, which is a tactic that some government departments have turned to after years of neglecting their record-keeping. This move was a result of the realisation that old ideas that had already failed were being recycled and presented as new and that a public historian, backed by a departmental library, could detect such trends and deliver policy advice that might warn decision-makers about the dangers of repeating history (Szreter 2011). However, as a minimum, better record-keeping means finding a way to store lessons so that they can be accessed easily. A key part of this is regarding the narratives and recording the nuance of past events and their relationships to reforms, procedures and behaviours. In this way, the 'why' behind business-as-usual can be explained. Finally, recordkeeping ought to extend into the uncertainty of the emergency relief phase when possible. There is no doubt that those in the thick of a disaster zone are not going to prioritise the historical record when taking decisions. In fact, they may be uncomfortable with it at a fundamental level because of the shadow of post-crisis accountability and censure. However, by allocating specific resources to record-keeping, hard won experiences about what works in the heat of a disaster can be preserved across staff rotations. This is enough of a reason to at least trial the use of professional record-keepers in a crisis response. Ethnographers with disaster experience, for example, would be particularly useful in this regard.

\section{Use External Memory.}

\section{Scope out and connect with external} organisations who have expertise. Specialists that operate outside of fast-churning sectors can be a valuable repository of memory.

For many government agencies, NGOs can act as a form of external memory. This is because they are relatively stable in their policy focus and because their core advocacy messages tend to remain consistent over time. However, there is nothing to suggest that NGOs themselves cannot draw on external memory in the same way. The most obvious example is the research centre. Although they are also subject to the whims of external funding, long-running centres will have significant levels of institutional memory. Indeed, specialisation and expertise within an organisation is often an indicator of the likelihood of strong memory (Stark 2019). However, other bodies also have untapped stores of external memory. Trade unions and professional associations, for example, are often stable organisations with wellrecorded histories and long-serving staff that will be able to recall sectoral trends.

The most compelling source of external memory is to be found in local capacities. Cultivating national platforms, local NGOs and indigenous participatory institutions around the world, for example, means supporting them to record and share their histories as a means of memory building. This agenda also contributes to an empowering form of development. Humanitarian agencies should therefore scan their networks, seek out external memory and build relationships in ways that could allow it to be tapped.

\section{Increase Storytelling.}

\section{Stories of success and failure can propagate}

lessons across time and bridge the gap

between outgoing and ingoing staff. Effort

should be made to tell historical lessons as part of induction and basic training.

When thinking about enhancing memory, most organisations opt for the formal-institutional route. This means attempting to retain staff and embed lessons into formal procedures. However, storytelling is a crucial but neglected dimension of memory building that is easy to do, cost-efficient and can offer real returns. Organisations simply do not do it as they are too focused on daily business. However, perpetuating stories from the past, which teach new and existing actors about organisational history, can be something that is woven into business-as-usual practices. A simple means, for example, would be to include history in staff inductions and forms of basic training. Ethnographic organisational 
research tells us that newly arrived leaders often adopt and then quickly invoke stories from their organisation's past as a means of legitimising themselves (Linde 2009). This is one way in which memory passes over from old leaders to new incumbents. This type of appropriation could be extended to all staff via training processes.

\section{Use Coordination Mechanisms for Knowledge Transfer. \\ Coordination mechanisms are a constant \\ feature of disasters and can be used as a \\ short-term repository for historical knowledge.}

Whether it's the cluster framework at the international level or a domestic coordination framework like AIIMS or ICS, their purpose is to coordinate by centralising knowledge across a variety of different actors. This means that coordination mechanisms are a means of knowledge transfer across time. Moreover, coordination frameworks are a constant feature in disasters and remain while staff come and go. This means that they have the potential to reduce the memory-loss that occurs through staff handovers. Ideally, this responsibility should be given to the 'logistics' team within the coordination framework. Logistics capacities are a generic feature of most coordination frameworks, they are typically responsible for information management and logistics research has addressed issues of memory and memory-loss. Logistics teams could therefore take carriage of a record-keeping responsibility, which would then be used during handover periods. Of course, the assumption being made here is that humanitarian actors will be engaging with inter-organisational coordination mechanisms, which is not always a given.

\section{Conclusion}

It is time for those who prepare and respond to humanitarian crises to start taking institutional amnesia seriously. It can be the cause of lesson-learning failures, it can undermine the quality of emergency decisionmaking and operational processes, and it can fuel problematic forms of post-crisis politics. Ultimately, however, the single biggest reason why humanitarian agencies need to recognise memory-loss is because it is the dynamic which ensures that problematic pasts, which are registered in the causes of disasters and the issues that lead to their mishandling, return again and again to haunt humanitarian responses.

When amnesia is ignored misdiagnoses occur and reforms miss the mark. We tell ourselves that we can fix cyclical problems by remedying how we learn, or by getting to grips with coordination failures or by increasing the use of evidence and research in planning efforts. These are all worthy endeavours, which will certainly improve disaster management efforts, but they are meaningless if they are forgotten because of the individual, organisational and network dynamics discussed above. If we really want to treat the pathologies that have created long-running problems in humanitarian responses to crises, we will need to work out how to remember them across time. 
Assmann, A. (1999). Erinnerungsräume: Formen und Wandlungen des kulturellen Gedächtnisses. (Munich: Verlag C.H. Beck.

Baddeley, A. (2007). Working Memory, Thought, and Action. Oxford: Oxford University Press.

Barakat, S., Deely, S., and Zyck, A. (2010). 'A tradition of forgetting': stabilisation and humanitarian action in historical perspective. Disasters, 34(S3): S297-S319

Beck, U. (1992). Risk Society: Towards a New Modernity. Sage Publications.

Bell, D. (2006). 'Introduction: Memory, Trauma and World Politics' in Bell, D (ed). Memory, Trauma and World Politics: Reflections on the Relationship Between Past and Present, Basingstoke: Palgrave.

Bevir, M., \& Rhodes, R.A.W. (2010). The State as Cultural Practice. New York: Oxford University Press.

Boin, A., McConnell, A and 't Hart, P. (2008). Governing after Crises: The Politics of Investigation, Accountability and Learning. Cambridge: Cambridge University Press.

Boje, D. 2008. Storytelling Organizations. London: Sage Publications.

Clarke, M., Fanany, I and Kenny, S. (2010) Post-Disaster Reconstruction: Lessons from Aceh. London: Earthscan.

Colten, C.E and Sumpter, A.R. (2009). 'Social memory and resilience in New Orleans'. Natural Hazards. 48: 355-364.

Connerton, P. (1989). How Societies Remember. Cambridge: Cambridge University Press.

Corbett, J, Grube, D.C, Lovell, H and Scott, R. (2018) 'Singular memory or institutional memories? Toward a dynamic approach'. Governance. 31 (3): 555-573.

Drennan, L., McConnell, A. and Stark, A. (2015). Risk and Crisis Management in the Public Sector, 2nd edition. Abingdon: Routledge.

Dubey, R. Gunasekaran, A., Altay, N., Childe, S.J and Papadopoulos, T. (2016). Understanding employee turnover in humanitarian organizations. Industrial and Commercial Training, 48 (4): 208-214.

Eburn, M and Dovers, S (2015), 'Learning Lessons from Disasters: Alternatives to Royal Commissions and Other Quasi-Judicial Inquiries', Australian Journal of Public Administration, 74 (4): 495-508

Edkins, J. (2003). Trauma and the Memory of Politics. Cambridge: Cambridge University Press.
Elliott, D. (2009). 'The Failure of Organizational Learning from Crisis - A Matter of Life and Death?'. Journal of Contingencies and Crisis Management. 17 (3): 157-168.

Halbwachs, M. (1992). On Collective Memory. Chicago: Chicago University Press.

't Hart, P and Boin, A, (2001) 'Between Crisis and Normalcy: The Long Shadow of Post-Crisis Politics' in Rosenthal, U, Boin and Comfort L.K (eds), Managing Crises: Threats, Dilemmas, Opportunities. Springfield: Charles C Thomas.

Hicks, E and Pappas. G. (2006). 'Coordinating Disaster Relief after the South Asia Earthquake'. Society. July/ August: 42-50.

Hilhorst, D and Schmiemann, N. (2002) Humanitarian principles and organisational culture: Everyday practice in Meédecins Sans Frontié res-Holland. Development in Practice, 12 (3-4): 490-500.

Hindmoor, A and McConnell, A. (2013) 'Why didn't they see it coming? Warning signs, acceptable risk and the global financial crisis'. Political Studies. 61: 543-560.

de Holan, P.M. (2011). Organizational Forgetting, Unlearning, and Memory Systems. Journal of Management Inquiry 20(3):302-304.

Kliegel, M., McDaniel, M.A and Einstein, G.O. (2008). Prospective Memory: Cognitive, Neuroscience, Developmental and Applied Perspectives. New York: Lawrence Erlbaum Associates.

Korff, V.P., Balbo, N., Mills, M., Heyse, L and Wittek, R. (2015) The impact of humanitarian context conditions and individual characteristics on aid worker retention. Disasters, 39(3): 522-545.

Levitt, B. and March, J.G. (1988). Organizational learning. Annual Review of Sociology 14: 319-340.

Loquercio, D., Hammersley, M. and Emmen, B. (2006). Understanding and addressing staff turnover in humanitarian agencies. Humanitarian Practice Network Paper. Available at: https://www.alnap.org/helplibrary/understanding-and-addressing-staff-turnoverin-humanitarian-agencies

Linde, C. (2009). Working the Past: Narrative and Institutional Memory. Oxford: Oxford University Press.

March, J.G. (2010) The Ambiguities of Experience. Ithaca N.Y: Cornell University Press. 
McDaniel, M.A and Einstein, G.O. (2007). Prospective Memory: An Overview and Synthesis of an Emerging Field. Thousand Oaks sCA: Sage.

Misztal, B.A. (2003). Theories of social remembering. Maidenhead: Open University Press.

Moynihan, D.P. (2008). 'Learning under Uncertainty: Networks in Crisis Management'. Public Administration Review. 68(2): 350-365.

Natsios, P. (1995). NGOs and the UN system in complex humanitarian emergencies: Conflict or cooperation? Third World Quarterly, 16 (3): 405-420.

Olick, J.K and Demetriou, C. (2006). 'From Theodicy to Ressentiment: Trauma and the Ages of Compensation' in Bell, D (ed). Memory, Trauma and World Politics: Reflections on the Relationship Between Past and Present, Basingstoke: Palgrave.

Perrow, C. (2007). The next catastrophe : reducing our vulnerabilities to natural, industrial, and terrorist disasters. Princeton NJ: Princeton University Press.

Pollitt, C. (2000). Institutional Amnesia: A Paradox of the "Information Age". Prometheus 19(1):5-16.

Pollitt, C. (2009). Bureaucracies Remember, Post-bureaucratic Organizations Forget? Public Administration 87(2):198-218.

Richardson, F. (2006). Meeting the demand for skilled and experienced humanitarian workers. Development in Practice, 16 (3-4): 334-341.

Roth, S. (2012), 'Professionalisation trends and inequality: experiences and practices in aid relationships',

Third World Quarterly, 33 (8): 1459-74.

Szreter, S. (2011). History and Public Policy in Bate, J (ed) The Public Value of the Humanities. London: Bloomsbury, pp. 219-231.

Stark, A. (2014). 'Bureaucratic values and resilience: an exploration of crisis management adaptation'. Public Administration. 92 (3): 692-706.

Stark, A. (2018). Public Inquiries, Policy Learning and Threat of Future Crises. Oxford: Oxford University Press.

Stark, A. (2019). 'Explaining Institutional Amnesia in Government'. Governance, 32 (1): 143-158.

Stark, A and Head, B. (2018). Institutional Amnesia and Public Policy. Journal of European Public Policy. (Early View) doi:10.1080/13501763.2018.1535612.

Stumpenhorst, M., Stumpenhorst, R., and Razum, O. (2011). The UNOCHA cluster approach. Gaps between theory and practice. Journal of Public Health. 19 (6):587592.
Tatham, P. and Kovács, G. (2010), 'The application of 'swift trust' to humanitarian logistics', International Journal of Production Economics, 126 (1): 35-45.

Telford, J and Cosgrave, J. (2007) The international humanitarian system and the 2004 Indian Ocean earthquake and tsunamis. Disasters, 31(1): 1-28.

Terry, F. (2002). Condemned to Repeat? The Paradox of Humanitarian Action. London. Cornell University Press.

Tomasini, R.M. and Van Wassenhove, L.N. (2009), 'From preparedness to partnerships: case study research on humanitarian logistics'. International Transactions in Operational Research, 16 (5): 549-59.

Walsh, J.P and Ungson, G.R (1991). 'Organizational Memory'. The Academy of Management Review 16(1):57-91.

Weick, K.E. (1988) 'Enacted Sensemaking in Crisis Situations'. Journal of Management Studies, 25 (4): 305317.

Weiss, G. (1999). Principles, Politics, and Humanitarian Action. Ethics \& International Affairs, 13:1-22.

Wright, D.B and Gaskell, G.D. (1995). 'Flashbulb Memories; Conceptual and Methodological Issues'. Memory. 3: 67-80. 